\title{
International Journal of
}

\section{Modern Education and Computer Science}

\section{Kol.8}

No.7 Jul. 2016

\section{IJMECS Kol.8} Http:// www.mecs-press .org Vol. 8 No.7 July 2016

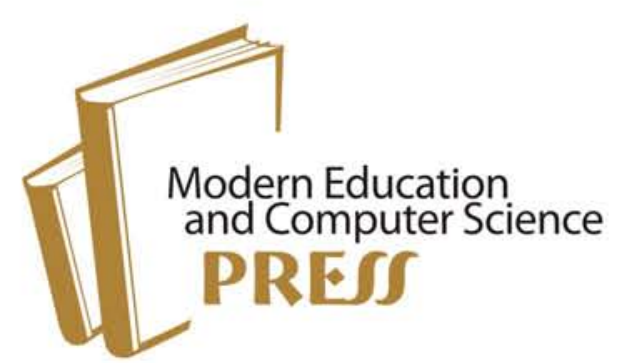




\section{International Journal of Modern Education and Computer Science (IJMECS)}

ISSN Print: 2075-0161, ISSN Online: 2075-017X

Volume 8, Number 7, July 2016

\section{Contents}

\section{REGULAR PAPERS}

The Effect of MySQL Workbench in Teaching Entity-Relationship Diagram (ERD) to Relational 1 Schema Mapping

Li Yang, Li Cao

The Proposed Methods to Improve Teaching of Software Engineering

Afra A. Alabbadi, Rizwan J. Qureshi

Speed Learning: Maximizing Student Learning and Engagement in a Limited Amount of Time

Arshia A. Khan, Janna Madden

Detecting Anomalies in Students' Results Using Decision Trees

Hamza O. Salami, Ruqayyah S. Ibrahim, Mohammed O. Yahaya

Modular Design of $2^{\mathrm{n}}: 1$ Quantum Dot Cellular Automata Multiplexers and its Application, via Clock

Zone based Crossover

Sonali Singh, Shraddha Pandey, Subodh Wairya

An Analysis of Performance Testing in Distributed Software Applications

Muhammad Fraz Malik, M. N. A. Khan

Machine Learning Cross Layer Technique to Detect Sink Hole Attacks in MANET

G.Usha, K.Mahalakshmi

Email Spam Detection Using Combination of Particle Swarm Optimization and Artificial Neural

Mohammad Zavvar, Meysam Rezaei, Shole Garavand 